\title{
DERIVA URBANA COMO PEDAGOGÍA EN AULAS DE ARTE
}

\author{
URBAN DÉRIVE AS PEDAGOGY IN ART CLASSROOMS
}

\section{Noelia Paz Fernández}

Universidad de A Coruña (1) https://orcid.org/0000-0002-5822-3704

\section{Resumen}

La práctica de la deriva urbana, aunque conceptualmente nace principalmente del situacionismo, en un espectro ampliado se ha llevado a cabo a lo largo de toda la historia, pues es el acto de caminar y deambular para descubrir, es una acción inherente al ser humano. En el contexto educativo, ofrece la oportunidad de una metodología de inmersión en los espacios tanto físicos como conceptuales, sirviendo de catalizador para generar procesos, prácticas artísticas multitextuales o reflexiones en torno a los elementos que configuran dichos espacios. Es una forma de pensar la ciudad y también de ser partícipe de ella.

En el presente artículo analizamos la experiencia de deriva urbana llevada a cabo en la EASD Pablo Picasso con uno de los grupos de alumnado, suponiendo una salida del centro educativo y propiciando procesos colectivos e individuales acerca del conocimiento del entorno urbano local.

\section{Palabras clave}

Deriva urbana; aula; ciudad; pedagogías alternativas; práctica artística.

\section{Abstract}

The practice of dérive, despite being conceptually born mainly from situationism, has in a broader spectrum been carried out throughout history. As it is the act of walking and wandering to discover, it is also an action inherent to the human being. In the educational context, it offers the opportunity of an immersion methodology in both physical and conceptual spaces, serving as a catalyst to generate processes, multi-textual artistic practices or reflections on the elements that make up these spaces. It is a way of thinking about the city and also of being a part of it.

In this article we analyze the experience of urban dérive carried out at the Pablo Picasso Art and Design College with one of the groups of students, who undertook a study away from the educational centre to promote collective and individual processes about the knowledge of the local urban environment.

\section{Key words}

Dérive; classroom; city; alternative pedagogies; artistic practice.

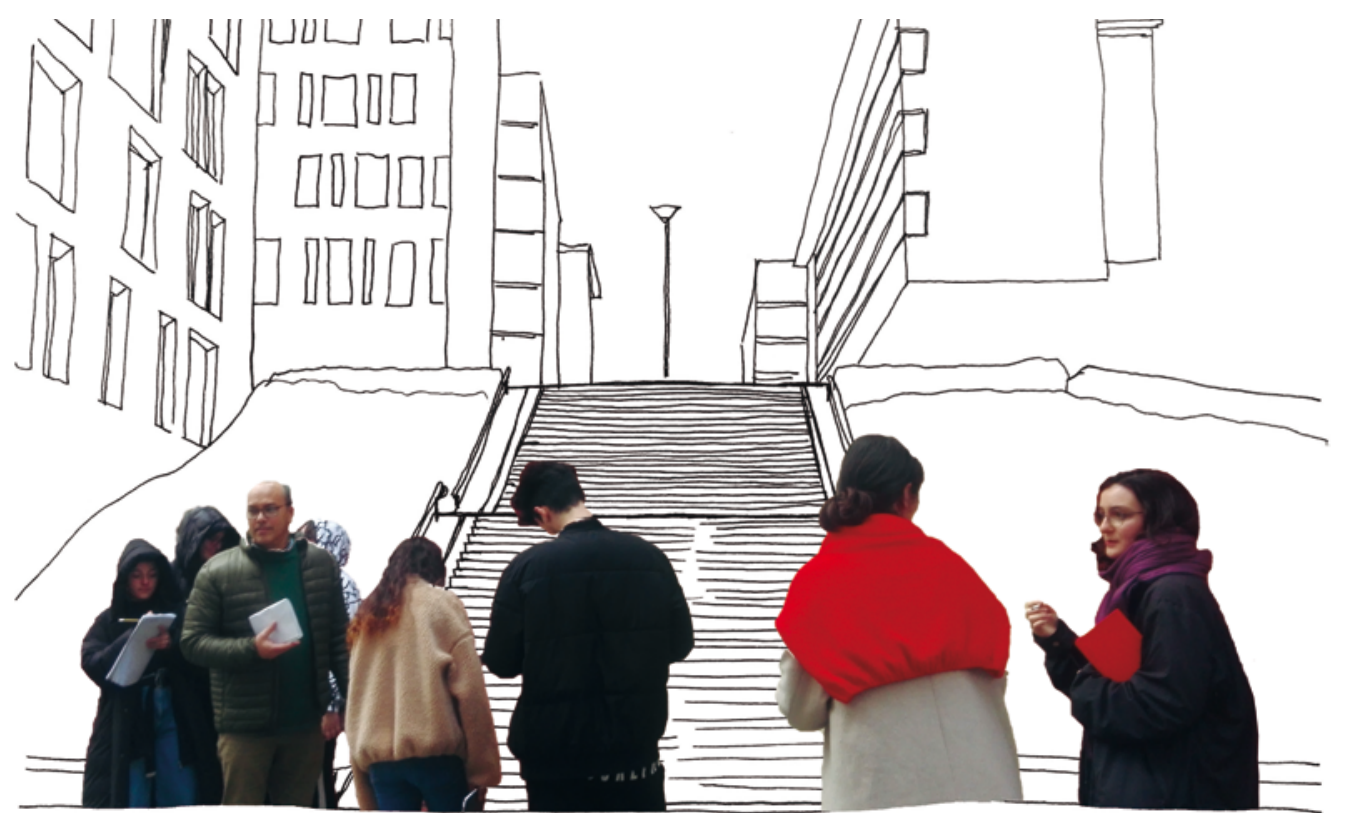

Image 1. Collage based on the photographs taken during the urban dérive with the students from the EASD Pablo Picasso (A Coruña). Source: self made. 
[...] la deriva se presenta como una técnica de paso ininterrumpido a través de ambientes diversos. El concepto de deriva está ligado indisolublemente al reconocimiento de efectos de naturaleza psicogeográfica, y a la afirmación de un comportamiento lúdico-constructivo, lo que la opone en todos los aspectos a las nociones clásicas de viaje y de paseo. Una o varias personas que se abandonan a la deriva renuncian durante un tiempo más o menos largo a los motivos para desplazarse o actuar normales en las relaciones, trabajos y entretenimientos que les son propios, para dejarse llevar por las solicitaciones del terreno y los encuentros que a él corresponden. (Debord, 1958, p. 50)

\section{INTRODUCCIÓN}

Este artículo se centra en la hipótesis de la deriva urbana como recurso pedagógico en la enseñanza artística, proponiendo un ámbito de intención para pensar la ciudad, ofrecer una vía de interacción con el entorno urbano, al traspasar los muros del aula, y aproximarse al proceso de hacer ciudad desde la educación como campo activo participante en los diálogos de la sociedad y la ciudad contemporánea en la esfera pública.

Según Francesco Careri (2002) el andar como práctica estética tiene por origen la necesidad natural de moverse por el territorio con el fin de encontrar alimentos e información vital para la supervivencia. Pero una vez cubiertas esas exigencias primarias, el hecho de caminar se transformó en una acción simbólica que posibilitó que el hombre habitara el mundo. El autor toma el concepto de la trashumancia nómada como arquetipo de cualquier recorrido, remontándose al pasado con la realidad del Paleolítico y con los significados simbólicos que fueron trasladados por la cultura egipcia por medio del ka, el símbolo del eterno errar: "en la actualidad podríamos construir una historia del andar como forma de intervención urbana, que contiene los significados simbólicos de aquel acto creativo primitivo: el errar, en tanto que arquitectura del paisaje, entendiendo por 'paisaje' el acto de transformación simbólica, y no solo física, del espacio antrópico" (Careri, 2002, p. 20).

Tomamos el acto de andar desde la perspectiva de la deriva situacionista contemplando las características destacadas por Careri como ciudad lúdica y nómada, ciudad colectiva que no solo se orienta hacia la determinación y exploración de las zonas ocultas e inconscientes de la ciudad, sino que se plantea investigar soportando sus bases en el concepto de "psicogeografía", es decir, el estudio de los efectos y las formas del ambiente geográfico en las emociones y el comportamiento de las personas, "Ios efectos psíquicos que el contexto urbano produce en los individuos" (Careri, 2002, p. 92). La aventura de explorar no organizadamente el entorno puede convertirse en una herramienta crítica y una práctica estética que propicie el descubrimiento de zonas escondidas, ocultas, vacías y olvidadas de la ciudad, conferirles un nombre y resignificarlas (Carbonell, 2015, p. 38). Surge con este acto, la posibilidad de perderse por la ciudad como una manera de exponerse al factor sorpresa de lo imprevisto e imprevisible. Ese paseo pone a prueba la sensibilidad, la diversidad de dimensiones perceptivas estimuladas por aquello encontrado, recreando y enriqueciendo el proceso de subjetivación del sujeto.

El presente texto expone, en primer lugar, la intención y la necesidad de abordar un enfoque pedagógico alternativo al institucional, basándose en un contexto amplio de vinculación del espacio urbano como ámbito de interacción con el entorno social y físico próximo, de inspiración y estimulación del aprendizaje, de acción e intervención educativa y artística. Deviene aquí la práctica de la deriva urbana como proceso en sí mismo, para abordar la experiencia y encuentro con el espacio público extramuros al centro educativo formal, y, al mismo tiempo, deviene también en herramienta de la educación y de la práctica artística, no solo, en relación a la incursión en el lugar, sino vinculada a la gestación y desarrollo de propuestas de expresión creativa. Es así como consideramos 
precisa la conceptualización del currículum de la ciudad como pedagogía inherente al entorno urbano y nos aproximamos a aquellos tipos de espacios idóneos para acoger una práctica liberada en la que se propicie el descubrimiento de zonas, aspectos o dimensiones intrínsecas al espacio, refiriendo a lo que Foucault (1999) definía como "heterotopías".

Para abordar la triangulación de ciudad, espacio y arte, la investigación educativa basada en las artes - Arts Based Education Research - presenta una metodología próxima a la transdiciplinariedad, o incluso extradisciplinariedad (Holmes, 2007), propia de aquellas investigaciones que acompañan tanto a la actividad artística de carácter educativo como a la cualidad estética del proceso investigador y de la producción artística. La práctica de la deriva requiere de metodologías que contemplen la indagación, la observación sensible, el aprendizaje basado en la percepción de estímulos del espacio y la expresión de aquellos aspectos clave de cada experiencia, adoptando diversidad de formatos textuales: sonido, narrativas escritas, dibujos, collage, mapas, cartografías; en definitiva, mapeos de la experiencia vivencial originada en el "andar como práctica estética" (Careri, 2002) que abran un proceso de creación. Interviene aquí el concepto de "psicogeografía" (Debord, 1958).

Bajo estas premisas teóricas, se ha llevado a cabo una experiencia de deriva urbana con alumnado de la EASD Pablo Picasso de A Coruña. Se trata de una primera aproximación a la práctica grupal y, por ello, adopta un carácter introductorio. Ha generado, sin embargo, un proceso de implicación activo del alumnado, dando lugar a reflexiones que reflejan una interacción sensible y de valoración estética y personal del entorno urbano próximo. En este texto describimos la práctica realizada y algunos de sus resultados.

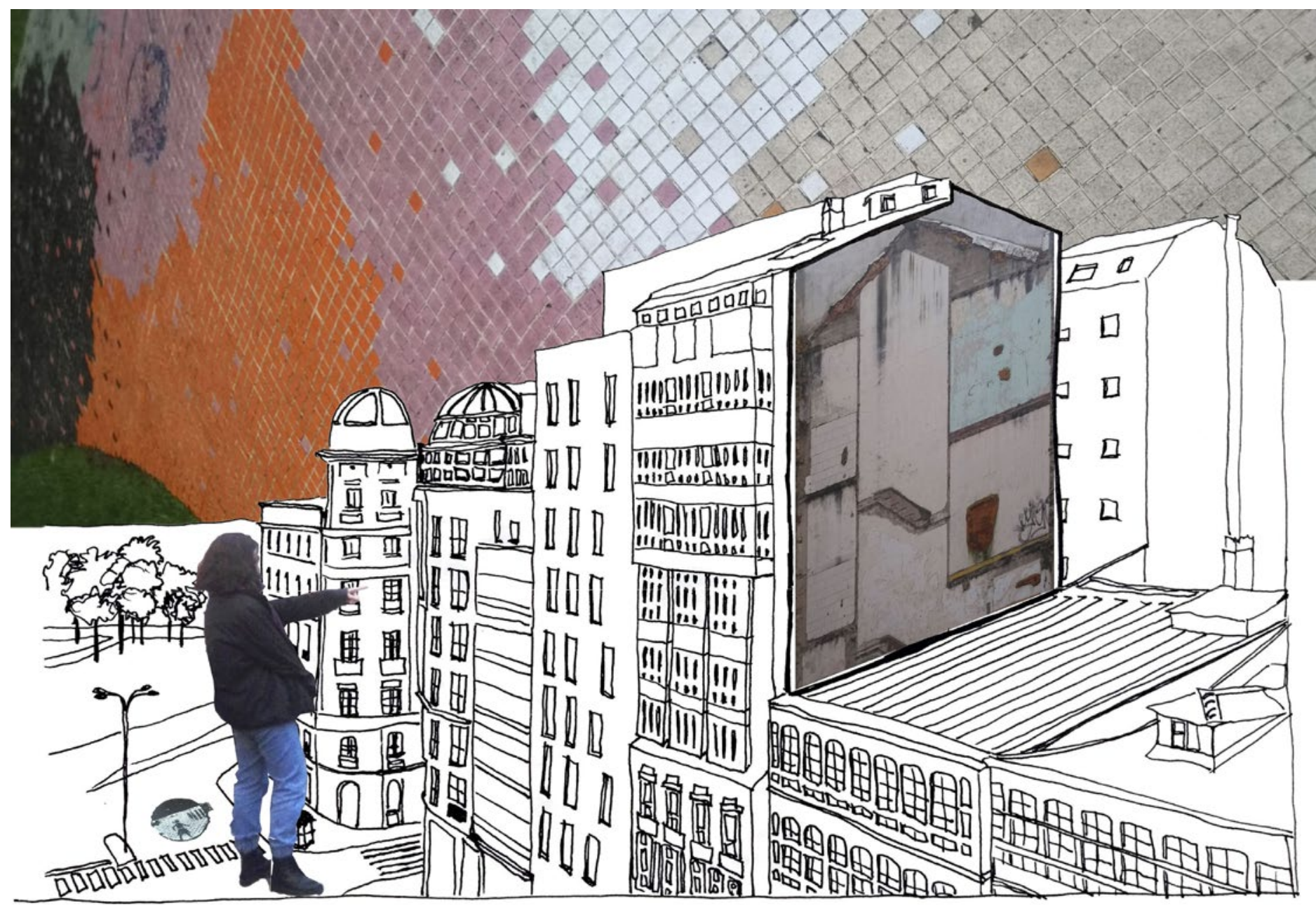

Imagen 2. Collage creado a partir de las fotografías tomadas durante la deriva urbana con el alumnado de la EASD Pablo Picasso (A Coruña). Fuente: autora. 


\title{
2. DERIVA URBANA COMO PEDAGOGÍA EN AULAS DE ARTE
}

El uso de la deriva urbana como acción educativa en el aula puede apuntar hacia la transgresión de las dinámicas aprendidas con anterioridad para conceder lugar a una interdisciplinariedad en la que puedan confluir aspectos ambientales, sociales, arquitectónicos, climáticos, configuradores del entorno que ponen a disposición de la persona observadora, en experimentación activa, cantidad de estímulos que proyectar en un ámbito de aprendizaje artístico desde el pensamiento crítico. El hecho de compartir esas mismas vivencias con otras personas integrantes del grupo, hace aflorar contraposiciones durante la puesta en común de perspectivas, así como también coincidencias en la percepción subjetiva, entre otras observaciones. Ese diálogo pone de manifiesto el material estético, emocional y cognitivo susceptible de generar materializaciones y prácticas artísticas en función de su contexto de emplazamiento. Amieva (2014) interconectaba los conceptos de arte, pedagogía y deriva como vértices de un mismo triángulo para configurar las bases de la deriva como metodología educativa, exponiendo que

\begin{abstract}
la intención de trabajar la deriva situacionista como herramienta pedagógica es desarrollar el aprendizaje no tanto sobre el arte sino a través de él. Favorecer el desarrollo de la imaginación y por lo tanto de un pensamiento considerablemente más libre que el de otros ámbitos formativos, la activación de la reflexión y el cuestionamiento crítico, así como el sentido de colaboración en las dinámicas de grupo (Amieva, 2014, p. 232).
\end{abstract}

Al encontrarnos investigando el contexto educativo, interesa explorar los aspectos pedagógicos de la experiencia urbana para introducirla en un contexto curricular de la educación formal, en el que pueda tener cabida y ser puesta en práctica como acción.

\subsection{El currículo de la ciudad}

Paul Duncum (2011), investigador en el contexto estadounidense, nos acerca modelos de educación artística basada en la comunidad, en los que la ubicación de la pedagogía de la enseñanza artística se desplaza del aula a la calle. Se trata de una apuesta por una educación artística crítica y basada en el lugar, "critical, place-based art education", argumentando que el aislamiento de la escuela de las comunidades económicas y humanas locales disminuye las responsabilidades públicas y democráticas de la institución educativa, pero que, sin embargo, el carácter de las escuelas se transforma cuando las comunidades y la localidad se convierten en el foco de la educación (Graham, 2009 en Duncum, 2011, p. 353).

En el contexto español, Jaume Martínez Bonafé (2010) profundiza sobre la cuestión de la ciudad como currículo, haciendo partícipes en la reflexión diversidad de ámbitos de conocimiento, tales como la sociología, la psicología ambiental, la antropología y estudios culturales, así como ciertas pinceladas de urbanismo y teoría del arte. El currículo de la ciudad está en disputa permanente con los currículos que se ofertan reglados en la escuela (Martínez Bonafé, 2010, p. 535). La pluralidad de la ciudad la convierte en un espacio complejo en el que se superponen capas como la dimensión estructural de la planificación urbana (movilidad, vivienda, parques...), la actividad laboral y comercial, la intimidad, la interacción social, la dimensión política, la identidad, el comportamiento social y valores culturales, el tránsito, el esparcimiento y ocio y el arte urbano, entre otras. Y todas esas capas se entrelazan y se transforman constantemente, a diferentes ritmos y velocidades. Cada ciudad está organizada bajo un precepto cultural, diseñada, orientada e incitada a que rijan unas normas de funcionamiento, estipuladas estas por poderes políticos, empresas privadas, expertos tecnócratas, diseñadores con un determinado sesgo y corrientes de pensamiento históricas; de modo que se promueve un orden preestablecido. Sin embargo, surgen de manera orgánica prácticas y discursos sociales espontáneos e impredecibles que forman parte de la vida ciudadana y determinan en gran medida la experiencia urbana. El currículo escolar, por su parte, no ha dejado permeabilizar este último aspecto pedagógico activo de la ciudad de manera activa, salvo 
programas de mediación cultural, como por ejemplo la perspectiva de la ciudad educadora, habiendo dificultado la comunicación entre esta y la educación formal.

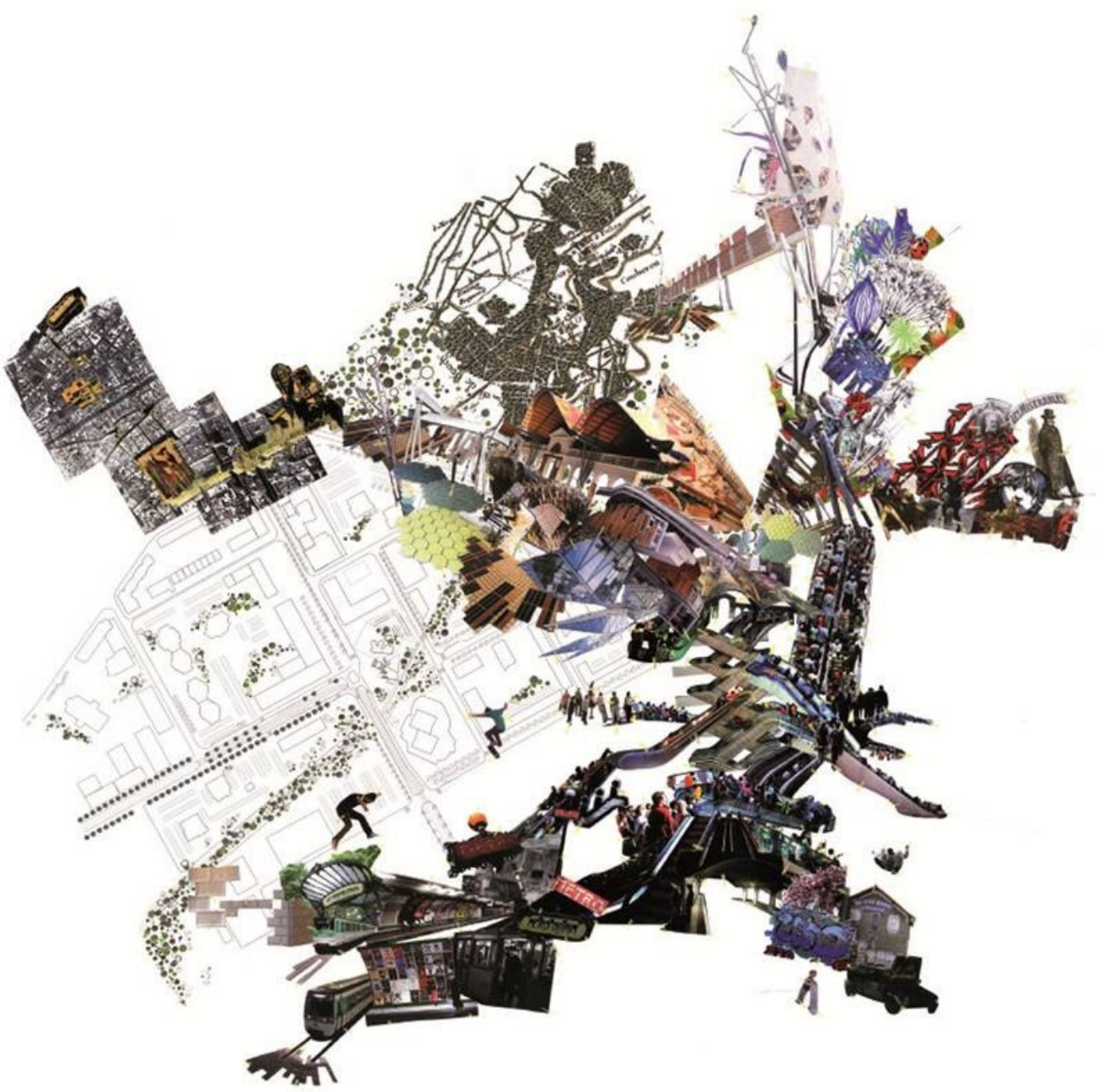

Imagen 3. Fotomontaje cartográfico. Fundación Enric Miralles - Pati Nuñez Agency - Programa de Posgrado en Regeneración Urbana

Desde una aproximación también transversal, Amparo Alonso Sanz (2018) resalta la importancia de los estudios de género, el urbanismo de género y la mirada interseccional para abordar el enfoque crítico que el encuentro con el entorno urbano puede sugerir en el ámbito de la educación artística. La autora hace referencia a Basset (2004), resaltando que la deriva también se encuentra caracterizada "por una actitud crítica respecto al alcance hegemónico de la modernidad. Y es aquí donde nos planteamos la hegemonía del patriarcado y sus efectos en la ciudad, aspectos que también precisan de una revisión profunda" (Alonso-Sanz, 2020, p. 365).

A la hora de llevar a cabo experiencias de encuentro con el espacio urbano, podríamos preguntarnos qué tipos de espacios serían susceptibles de acoger prácticas de deriva urbana y de exploración de la ciudad que fuesen propuestas en contextos educativos de enseñanza artística. Foucault (1999) genera conceptualmente un cajón en el que apreciar la existencia de espacios inconclusos, con el objeto de significar funciones sociales evidentes, pero que simultáneamente esconden y ofrecen versatilidad de posibilidades de uso y significado. Observamos que surge el término de "contraespacios", para dar cabida a aquellos espacios que, sin estar diseñados a priori para ofrecer un uso polivalente, producen una apertura a la apropiación imaginativa de ellos, generando un espacio para la utopía, al mismo tiempo que para la funcionalidad para la que fueron concebidos originalmente.

Entre todos esos lugares [heterotopías] que se distinguen los unos de los otros, los hay que son absolutamente diferentes; lugares que se oponen 
a todos los demás y que de alguna manera están destinados a borrarlos, compensarlos, neutralizarlos o purificarlos. Son, en cierto modo, contraespacios. Los niños conocen perfectamente dichos contra-espacios, esas utopías localizadas: por supuesto, una de ellas es el fondo del jardín; [...] o bien, un jueves por la tarde, la cama de los padres (Foucault, 1999, p. 436).

Se colocan así, los contraespacios, como ámbitos del territorio urbano idóneos para ser intervenidos por la práctica artística en el contexto de la enseñanza artística, debido principalmente a una predisposición a generar un tipo de investigación extradisciplinar, término acuñado por Brian Holmes (2007, p. 2), en sintonía con la deriva urbana como herramienta de indagación y descubrimiento, susceptible de ser aplicada en casi cualquier ámbito disciplinar, para ofrecer así, una apertura y expansión de los rigurosos límites disciplinarios que definen cada lenguaje y área del conocimiento y que suponen un constreñimiento en la experimentación intersubjetiva, característica del arte contemporáneo. Esta misma lógica puede ser aplicada a la intervención artística en contraespacios del entorno público para aquellas prácticas enmarcadas en la educación artística (y no solo).
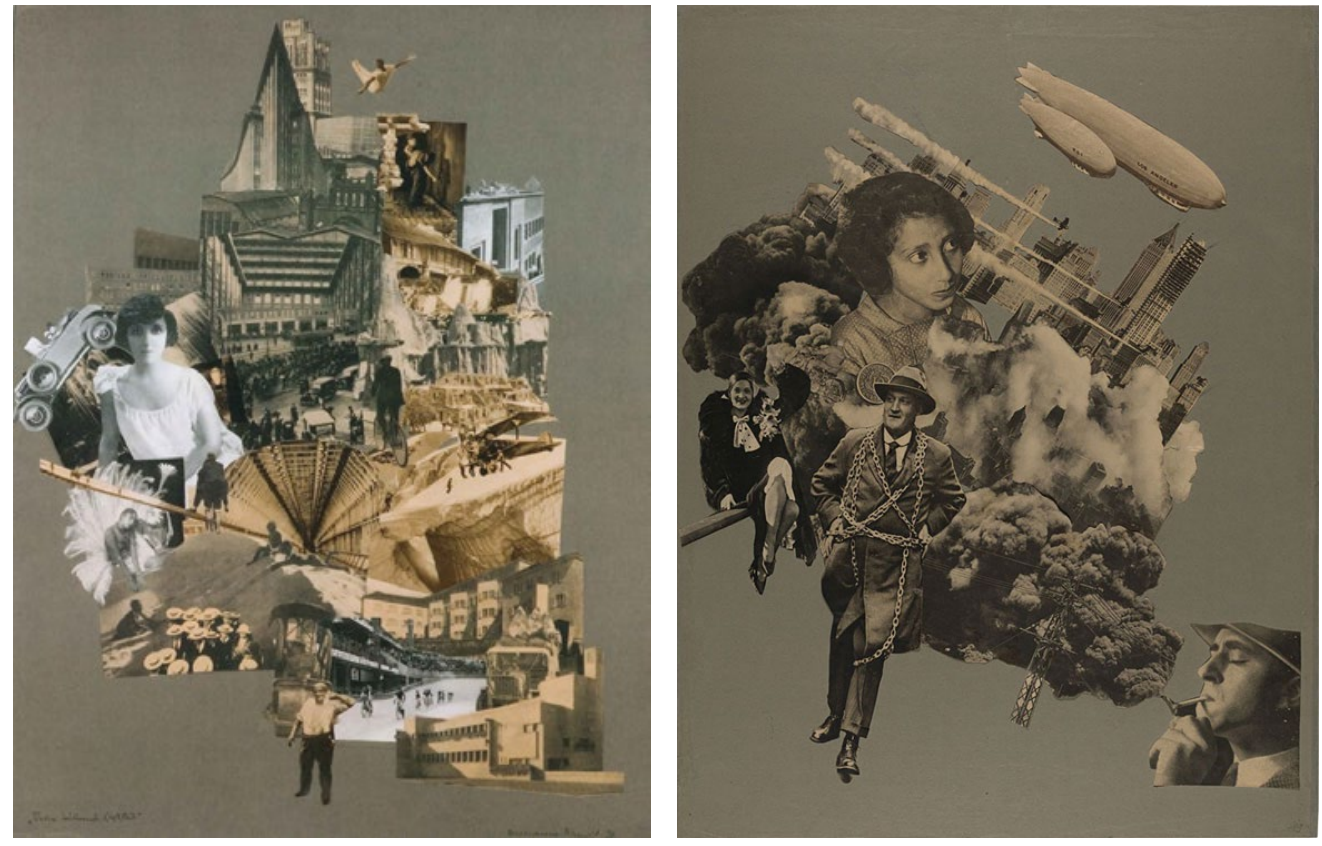

Imágenes 4 y 5. Fotomontajes de Marianne Brandt.

\subsection{La deriva como práctica pedagógica en la enseñanza ar- tística: metodología}

La deriva como recurso para la enseñanza e investigación es objeto de estudios recientes en el ámbito de la educación artística, como es el caso de la reflexión realizada por Ramón y Alonso-Sanz (2019), señalando que

Como opción pedagógica, un paseo por la ciudad, centrado en la búsqueda, tiene el potencial para mejorar la percepción y toma de conciencia de problemas que afectan a la población y deben ser abordados desde la educación. Entre los temas posibles de estudio destacan cuestiones como: aquellas relacionadas con el género, "surveillance, consumerism and safety in relation to men and women" (Bridger, 2013, p. 293); las letras, tipografía, relación con el patrimonio (Huerta, 2010, 2014); cultura popular, fiesta y etnografía (Bandeira \& Oliveira, 2017); y el desarrollo de competencias educativas en entornos de educación formal desde una vertiente crítica y una mirada estética (Ramon, 2013, 2015) (Ramón y Alonso-Sanz, 2019, p. 76). 
Estos autores vindican la deriva como método para la indagación, pero también como medio de construcción de conocimientos y como ejercicio artístico en sí mismo.

El carácter de los anteriores estudios, así como la investigación extradisciplinar apuntada por Holmes (2007), referencia y recuerda, por su forma de abordaje, al planteamiento de Arts-Based Education Research (ABER) en la medida en la que tiene como objetivo comprender la educación a través de conceptos, técnicas y prácticas basadas en las artes, contemplando el uso de gran variedad de metodologías basadas en la creación artística para llevar a cabo la propia investigación/experiencia y/o comunicar su comprensión a través de géneros tan diversos como la narrativa, la poesía, la pintura, la escultura, la fotografía, la ilustración, el teatro, la danza, la música, la performance. Es decir, sostiene una aproximación transdisciplinar que puede salir al encuentro de otras disciplinas que participen en el contexto tratado.

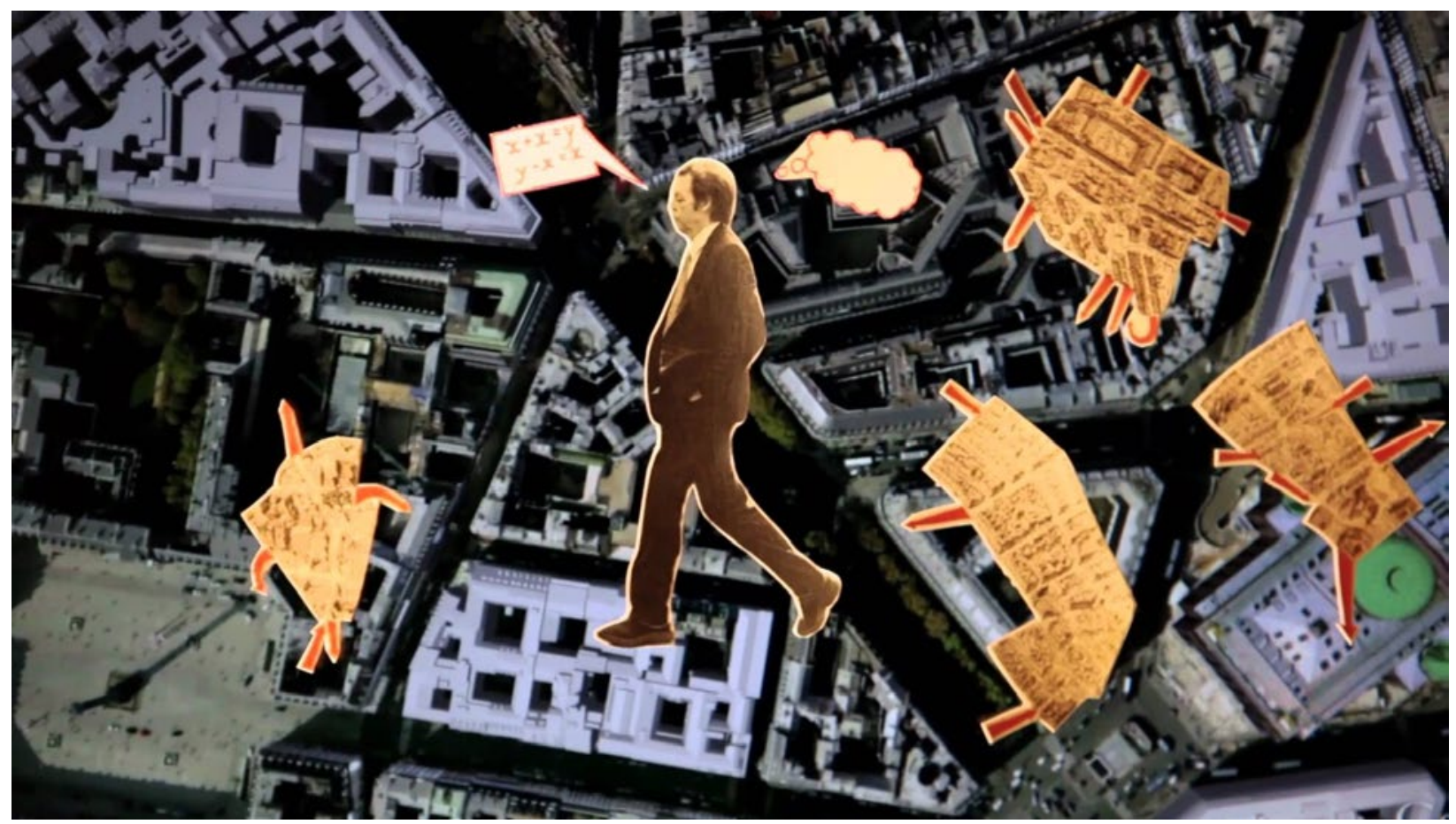

Imagen 6. Dérive App. Herramienta tecnológica de apoyo para realizar derivas urbanas.

Barone y Eisner (2006) apuntan que la ABER se basa en dos criterios inseparables, siendo el primero que esta pretende conferir intensidad a las acciones humanas vinculadas a la actividad artística, pero con carácter educativo, y el segundo criterio que la ABER se caracteriza por "la presencia de cualidades estéticas o elementos de diseño que acompañan, tanto al proceso investigador, como al objeto artístico elaborado durante la investigación" (Barone; Eisner, 2006 en Mesías-Lema, 2012, p. 53). Como señalan los autores, si aunamos estos dos criterios, podemos afirmar que la ABER tiene por particularidad un tipo de desarrollo en el que la persona investigadora se sirve de procedimientos, técnicas, documentos, metodologías y estrategias artísticas para "sacar a la luz su propia experiencia e interpretarla dentro del propio contexto en donde ésta se desarrolla" (Mesías-Lema, 2012, p. 53).

Genet (2016) realiza una exploración a fondo de la triangulación teórica ciudad - educación - arte y su aplicación práctica en el aula, a través de estrategias y metodologías tomadas del proceso creativo de las artes plásticas y visuales. La autora apunta que se puede decir que enseñar la ciudad es un trabajo relacionado con las disciplinas artísticas con finalidades sociales, pues el arte ofrece vías de expresión creativa para las relaciones humanas en las que se traduce la ciudad. Asimismo, Genet apoya parte de su reflexión teórica sobre la investigación de Huerta (2015), pues en dicha triangulación "La ciudad es nuestra aliada como espacio generoso para elaborar discursos nuevos desde el arte y la educación" (Huerta, 2015, en Genet, 2016, p. 50). 


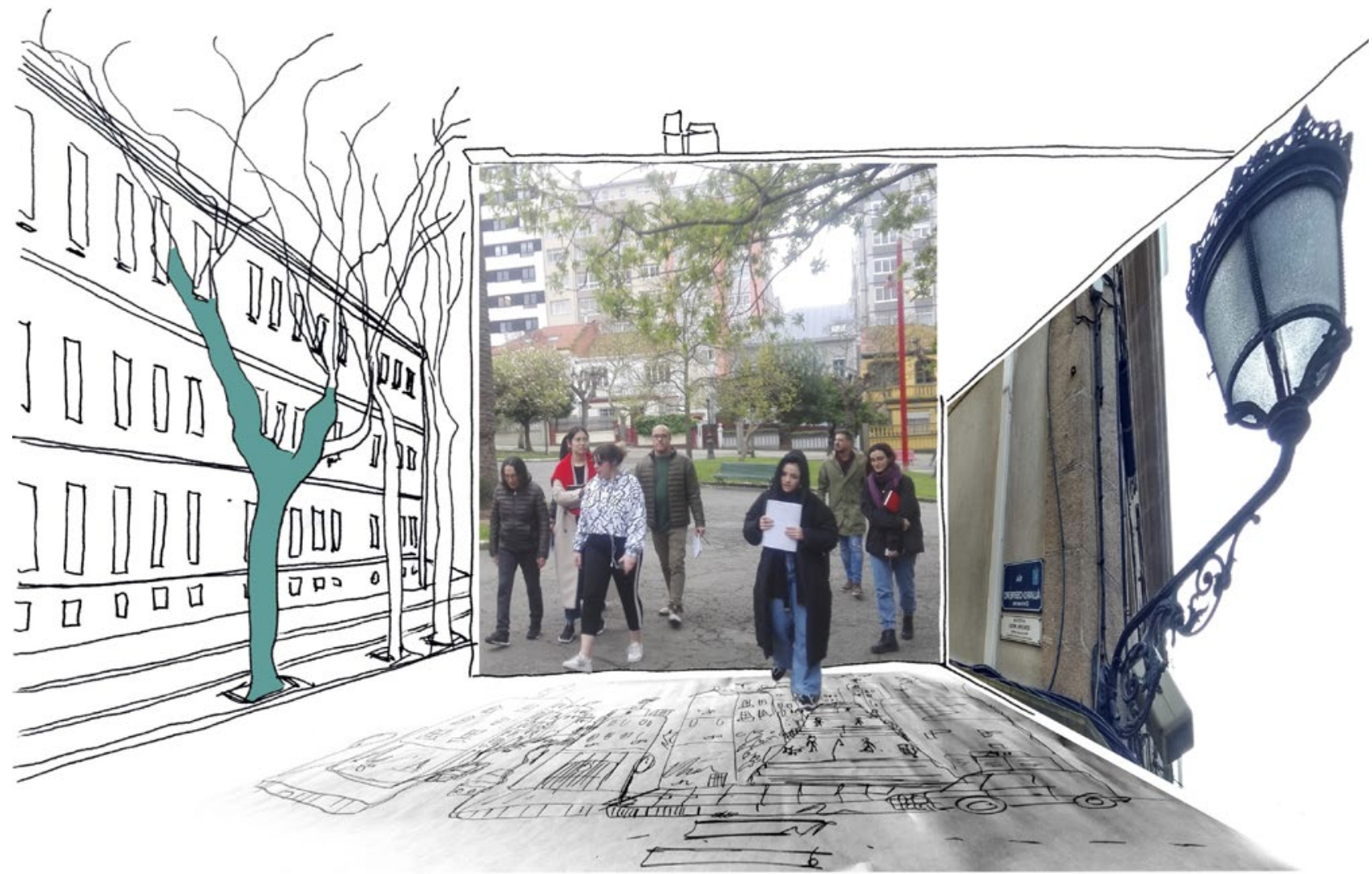

Imagen 7. Collage creado a partir de las fotografías tomadas durante la deriva urbana con el alumnado de la EASD Pablo Picasso (A Coruña). Fuente: autora.

Desde la mirada de la enseñanza artística, salta como un resorte el descifrar perspectivas estéticas y revelar la belleza contenida en su tejido complejo de una manera sensible que nos acerque a la imbricación de diferentes aspectos de la sociedad contemporánea (Genet, 2016, p. 50).

La cultura de la cotidianidad y la estética que generan los entornos habituales también representan un campo de acción que podemos convertir en laboratorio de ideas. El entorno urbano se nutre de las acciones de la ciudadanía, y el profesorado forma parte de ese entramado humano (Huerta, 2015, p. 62).

Genet subraya la dificultad para el alumnado de abarcar el conjunto de la ciudad debido a su escala y contenido, centrándose la mayoría de experiencias didácticas en espacios pequeños y actuaciones efímeras en ellos. Así, para conseguir entender la ciudad desde una perspectiva más global, se hace necesario apropiársela mediante otros medios, como por ejemplo la Teoría de la Deriva, que ya hemos mencionado con anterioridad, pues permite una búsqueda estética de lo inesperado. La autora destaca, a través de las investigaciones de Martínez Bonafé (2010), que también podemos observar la enseñanza de la ciudad como una "alfabetización crítica", pues podemos considerar la ciudad como un libro, es decir, "la ciudad es un lenguaje produciendo significaciones complementarias y antagónicas a la vez, alimentando así la libertad y la sujeción del sujeto, carne y piedra en mutua constitución" (Martínez Bonafé, 2010, p. 527). Esta investigadora se centra con su tesis en el aterrizaje de estrategias visuales que sirvan de base al aprendizaje, seleccionando principalmente instrumentos educativos ya asociados a enseñar la ciudad, como pueden ser la fotografía (narrativas visuales, series, fotomontajes), el mapa o el collage.

En el campo de la investigación a partir de las transformaciones (de los modos de funcionar como profesores y alumnos, de la implicación con el entorno, de la utilización de conceptos y objetos), el revulsivo que conocemos como Artography nos ofrece un panorama muy alentador, puesto que permite alterar y modificar una serie de elementos que hasta hace bien 
poco parecían intocables. Alumnado y profesorado establecen un equilibrio de significaciones que promueve la apropiación de los espacios y de los conceptos con intervenciones e instalaciones que divierten, atraen y ayudan a repensar nuestros lazos y experiencias, permitiendo transitar los espacios vacíos que normalmente son despreciados por otras metodologías de indagación (Huerta, 2018, p. 98).
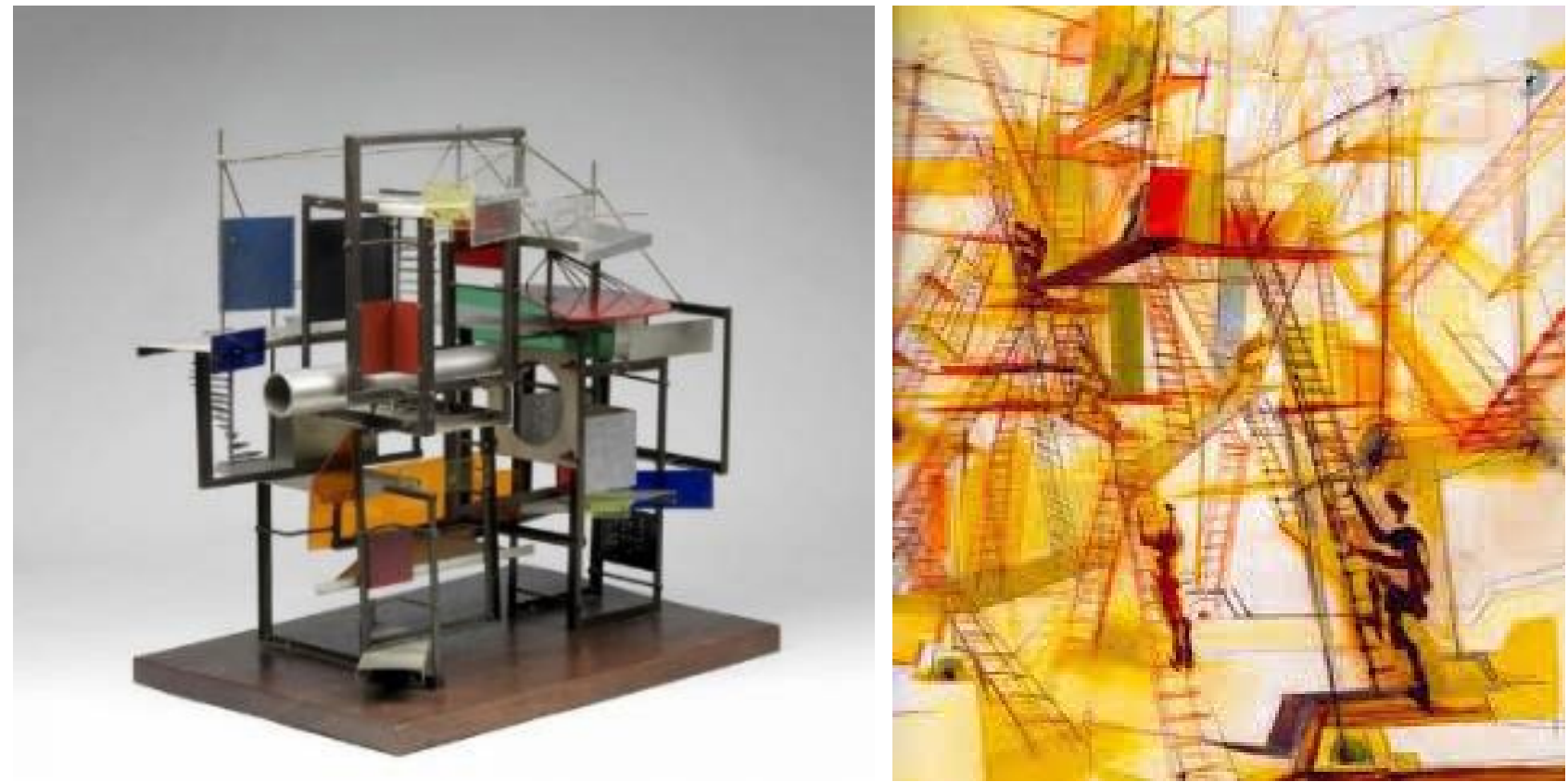

Imágenes 8 y 9. Obra de la serie "New Babylon" que Constant Nieuwenhuys produjo a modo de planificación de ciudades utópicas (1959) // "Laberinto de escaleras" de Constant Nieuwenhuys (1967) en el contexto de la Teoría de la Deriva de Guy Debord.

Asimismo, Alonso-Sanz (2020) hace de la contemporaneidad discursiva de la temática, una apuesta práctica, teórica y de vivencia personal tanto desde su posición de artista como investigadora y profesora, enfatizando la versatilidad de la cartografía como herramienta a través de la cual dar expresión a la psicogeografía y extenderla a multiplicidad de aplicaciones en el aula: desde el uso de geolocalizaciones de prácticas experienciales y consiguiente uso de las TIC, hasta la manifestación de diversas técnicas artísticas como el "registro auditivo de sonidos, elaboración de dibujos, toma de fotografías o vídeos y, anotación de narrativas" (Alonso-Sanz, 2020, p. 380). La autora reflexiona, tras haber puesto en marcha esta práctica en aulas de formación de profesorado de dibujo, que el uso de la cartografía ha llegado a extenderse como metodología y estrategia adoptada personalmente por el alumnado no solo en cuestiones de reflexión sobre la ciudad, sino también en ámbitos más ampliados de la relación "entre lugar y pensamiento asociado al espacio" (Alonso-Sanz, 2020, p. 383).

\subsection{La deriva en el aula: una investigación educativa basada en las artes en la EASD Pablo Picasso (A Coruña)}

Esta investigación empezó en el Ciclo Superior de Dorado, Plateado y Policromía, en la materia de Proyectos I, impartido en la EASD Pablo Picasso de la ciudad española A Coruña.

Con el fin de introducir conceptos de teoría del arte público, plantear aplicaciones y técnicas del dorado en exteriores y acercar al alumnado al espacio público como ámbito de práctica artística, y como primera toma de contacto para estudiantes no próximos al entorno urbano como ámbito de acción, consideramos apropiado proponer una salida del centro por el barrio de Monte Alto (colindante a las instalaciones de la escuela), apoyando así el guion de la primera sesión sobre una visita a obras artísticas de carácter arquitectónico y/o escultórico, pero con la principal intención de realizar una introducción a la práctica de deriva. 


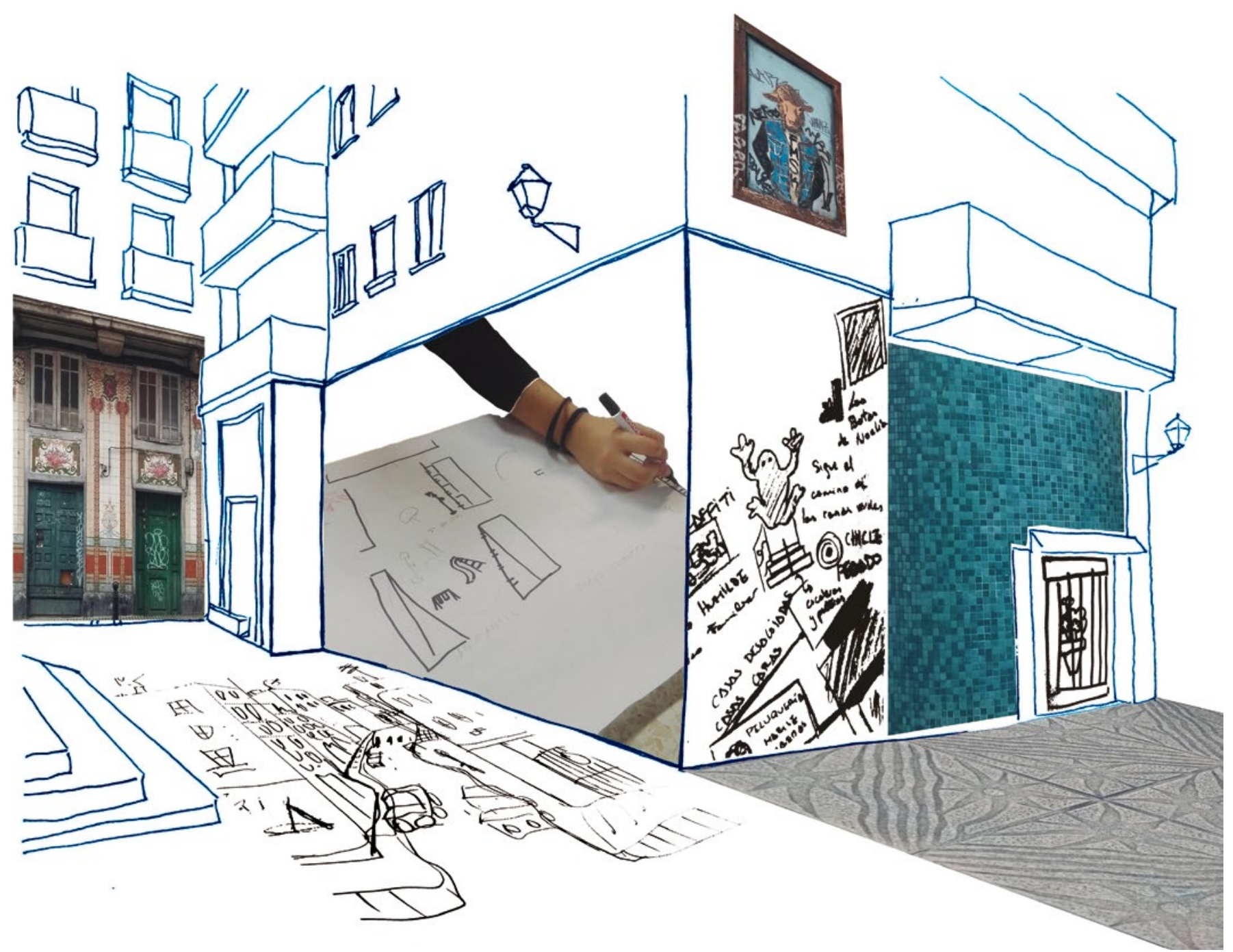

Imagen 10. Collage creado a partir de las fotografías tomadas durante la deriva urbana con el alumnado de la EASD Pablo Picasso (A Coruña). Fuente: autora.

La actividad se presentó como una deriva urbana grupal, que pusiese en práctica vivencial el concepto de psicogeografía sobre la que los situacionistas escribían en los años 60. A lo largo del recorrido, se activó el aspecto mayéutico a través de la interpelación al alumnado con preguntas orientadas a rebuscar en el paisaje, descubrir la configuración, ordenación y comportamiento del entorno urbano, dando rienda suelta a reconocer y diseminar estímulos externos, resortes internos asociados a ellos, preconcepciones, así como a vinculaciones emocionales con objetos o materiales o formas. Aunque idealmente esta práctica no debería ser guiada, la introducción a la práctica requería anotaciones que definiesen un marco de aproximación a la acción y un apunte sobre la finalidad para contextualizar la actividad.

Esta práctica de deriva pedagógica se planteó integrada en una unidad didáctica sobre arte en el espacio público, entendiendo que, para intervenir un lugar urbano, es necesario conocer qué factores juegan un papel en ese entorno. Así, en cada lugar se fueron planteando preguntas específicas para estimular el análisis y observación y así poder construir un conocimiento ligado al territorio. En este contexto educativo de iniciación a la deriva, no sería posible reducir la mayéutica a una sola pregunta, debido a la amplitud del tema y del espectro de elementos configuradores del entorno urbano, pero indicamos algunas de las preguntas que se fueron lanzando: ¿qué elementos estructuran las calles?; ¿qué hay en el suelo, plano horizontal?; ¿qué hay en el plano vertical?; ¿qué encontramos en el plano del aire?; ¿hay gente a nuestro alrededor?; ¿qué sonidos se perciben?; ¿hace frío, calor, viento?; ¿qué elementos tienen un diseño artístico?, ¿industrial?; ¿qué elementos podrían ser susceptibles de ser intervenidos con una propuesta artística?; ¿qué pasa si levantamos la mirada hacia arriba?, ¿qué encontramos?; ¿qué 
hay en los balcones y ventanas?, en su calidad de división de lo íntimo y lo público, ¿influyen en el aspecto de la calle?; ¿qué materiales componen esta plaza?; ¿cómo se ha diseñado la retícula de las calles y sus direcciones?; ¿qué vistas se perciben desde esta perspectiva?, ¿y desde esta otra?; ¿qué os llama la atención de este callejón?; etcétera.
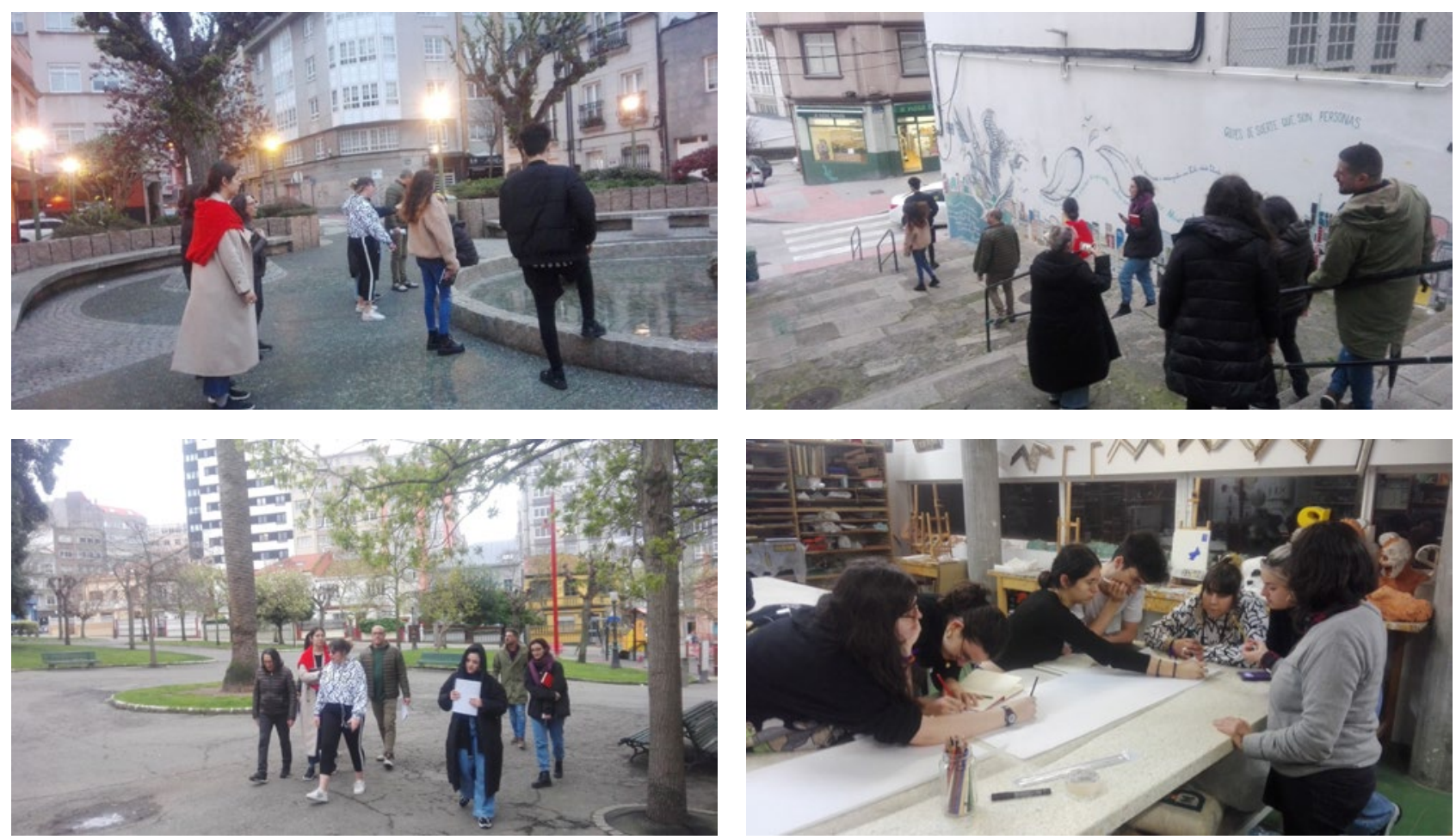

Imágenes 11. Fotografías tomadas durante la deriva urbana y la elaboración de una cartografía psicogeográfica con el alumnado de la EASD Pablo Picasso (A Coruña)

El comienzo de la actividad se caracterizó por una incertidumbre por parte del alumnado acerca de cómo adentrarse en el entorno afinando su percepción de los estímulos de alrededor en mayor medida que en su tránsito cotidiano. Las expectativas se presentaban inciertas y el objetivo se colocaba como difuso entre la experiencia básica de traspasar los muros del aula de entre lo que se podría sobreentender familiarmente como una excursión o paseo libre. En un primer momento, se propuso adoptar una mirada estética de los objetos del paisaje y del movimiento, flujos y dinámicas del espacio, observando qué elementos podrían ser susceptibles de ser intervenidos o cuáles podrían originar una obra artística o de qué manera se encontraban dispuestos intencionalmente (o no). Se introdujo un apunte sobre los planos que componen el espacio, siendo estos el plano vertical (paredes, muros, etc.), el plano horizontal (pavimento, suelos, elementos bidimensionales, etc.) y el plano del aire, sugestionando una observación multidireccional y analítica del lugar. Se incitó a conectar los posibles apuntes que fuesen surgiendo con historias o experiencias personales previas con ese mismo espacio o espacios análogos de su imaginario. Además, se invitó a tomar apuntes gráficos, a través del dibujo, de la fotografía, de la escritura o grabación de sonido. El alumnado comenzó a adentrarse en las propuestas, comentando detalles cada vez más propios y dando libertad al análisis individual de los lugares; y comenzaron a surgir pequeños grupos de conversación sobre elementos que llamaban su atención y desencadenaban nuevas preguntas y planteamientos mientras andábamos. Cabían apreciaciones profesionales, emocionales, técnicas, experienciales, poéticas, geográficas, acercándose progresivamente a aspectos subjetivos de la percepción del entorno y confiriéndole a la actividad calidades vivenciales.

Tras una hora de recorrido, regresamos al aula y se propuso realizar un mapa psicogeográfico configurado por aquellos detalles que fueron apareciendo durante la salida, definiendo así el territorio desde un punto de vista sensible y no (solamente) técnico. Se 
trató de un ejercicio a través del que dejarse soltar; resultó repentino y, en cierto modo, desubicador para una parte del alumnado. Sin embargo, estiramos hojas de papel continuo y todo el grupo hizo incursiones en el lienzo, retroalimentadas por una conversación colectiva argumentada de los comentarios, preguntas, diseños espaciales, dinámica social, etc. de los lugares caminados. A parte de una incursión colectiva fresca de la experiencia, se hacía preciso un vuelco de expresiones individuales y, con tal fin, se propuso un breve diario de campo en el que pudiesen recogerse percepciones a través de formato libre. En este espacio de reflexión personal subjetiva, encontramos el uso de la narración poética, de la fotografía y del dibujo como desencadenantes y formatos de expresión plástica de los estímulos particulares, además de posibles propuestas de intervención en el espacio urbano.

Cabe destacar reflexiones sobre la organización territorial, perspectivas buscadas del diseño, grupos sociales según zonas del barrio, flujos dependientes de las franjas horarias del día, actividad comercial de las calles, composiciones materiales de los elementos construidos, objetos abandonados o colocados intencionalmente por personas particulares, disposición del límite de lo privado y lo público, la ventana como entrada a la intimidad, la disposición y cuidado de elementos de jardinería, la relación de espacios con experiencias personales y la transformación de los lugares a través del tiempo.

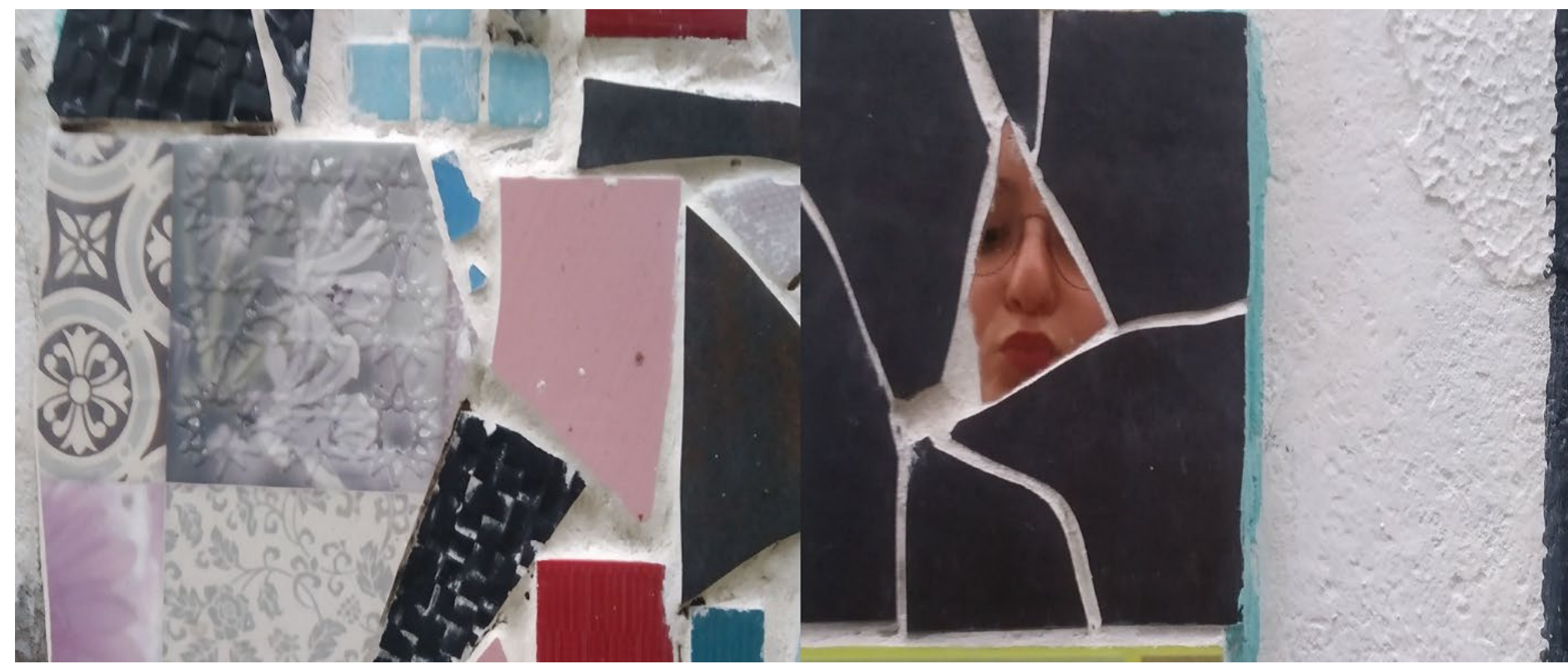

Imagen 12. Fotografía tomada por una alumna de la EASD Pablo Picasso (A Coruña) durante la deriva urbana.

\begin{abstract}
“Durante el recorrido, observamos diferentes espacios, como: calles, plazas, edificios y la interacción de la gente del barrio. Fue un paseo de contrastes, acostumbrados a la vida urbano-céntrica, este barrio refleja humildad y ofrece mucha cultura artística a nivel popular. Allí todo fluía de forma distinta, el ambiente era tranquilo, sin atascos por los coches y muy cercano. Los locales eran pequeños y modestos, con grandes escaparates y letreros para llamar la atención de los deambulantes"
\end{abstract}



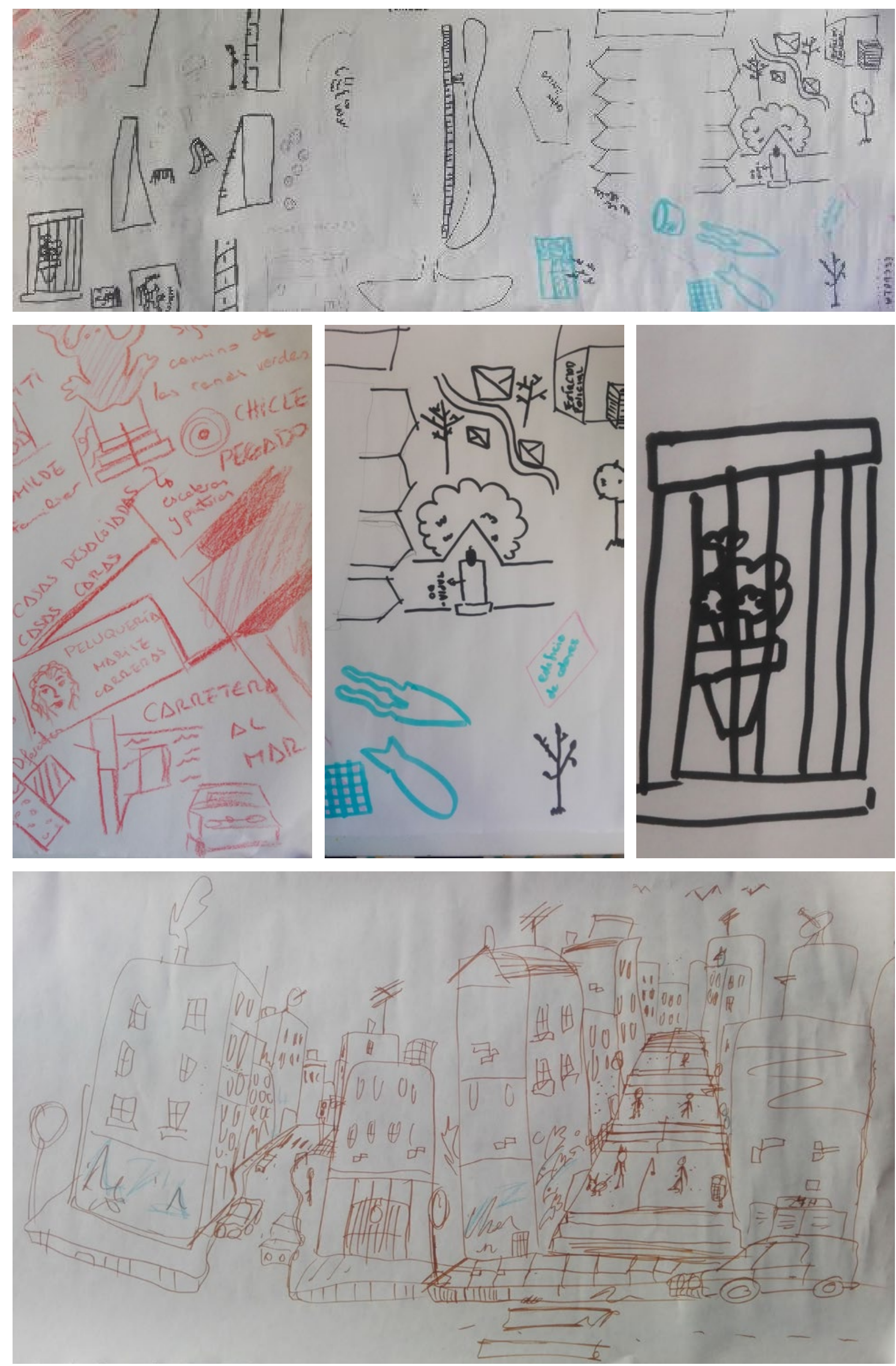

Imágenes 13. Fragmentos de la cartografía psicogeográfica creada por el alumnado de la EASD Pablo Picasso (A Coruña) tras la deriva urbana realizada. 
"Hai edificios. Moitos de distintas clases e cores, edificios que están e o espazo baleiro onde outros habitaban. Moitas portas, mais algunhas tapiadas, igual coas fiestras. A natureza tamén invade os espazos, non son só edificios, de forma planeada deixando sitio nas beirarrúas para que crezan árbores, parece un desfile militar, todas as árbores iguais, da mesma especie na mesma rúa, á mesma distancia, do mesmo tamaño. Noutros sitios hai árbores de folla caduca, pregúntome quen decidirá que tipo de árbore poñen en cada rúa, igual se é unha rúa pola que non hai moito vento poñen árbores caducas para que non voen moi lonxe as follas. Despois están as prantas que van crecendo en sitios onde non deberían, entre as baldosas da acera, nas fachadas dos edificios vellos, nos teitos e canalóns. Isto faime pensar que están intentando recuperar o que un día foi seu. E así chegamos as prantas de interior, que prantan os poboadores das estruturas que enmarcan as rúas (edificios), e a un curioso caso preto da rúa Adelaida Muro de prantas encerradas tras unha fiestra cunha verxa de ferro, parecendo así o cárcere, parece unha especie de performance ou obra teatral, incluso unha tentativa de violencia natural?"

(Alumna EASD Pablo Picasso, 2020)

"Antes de esta actividad, yo salía muchas veces a la calle a pasear con algún colega y nos sentábamos en algún lugar a procrastinar y ver pasar a la gente, yo además me fijaba mucho en el bullicio y en lo salpicado de elementos que está el entorno urbano. Todo eso me relaja y me gusta, ya que en mi arte siempre intento recargar el diseño con más y más elementos asemejándolo (salvando las distancias) a lo que se hacía en las catedrales barrocas, cargando de tantos elementos las fachadas y los interiores. Para mí una ciudad tiene esa misma carga de elementos: coches, señales, edificios, ventanales, plazas, bancos, farolas... y ruido, gente caminando y hablando, los coches acelerando o los semáforos dando la señal de que se puede cruzar, etc. Esta actividad me ha ayudado en centrarme en esta idea y a ver la ciudad con otros ojos" 


\section{REFLEXIONES FINALES: HACIA UNA INTEGRACIÓN DE LA DERIVA COMO PRÁCTICA PEDAGÓGICA EN EL CURRÍCULO FORMAL}

La puesta en práctica de la deriva en el aula podría, así, encontrarse inserta en una programación didáctica que se orientase con diversidad de objetivos, desde la práctica en sí misma, la generación de conocimiento, la observación de unos elementos concretos y la generación de una performance $u$ obra in situ o en movimiento, hasta su desarrollo como parte de la fundamentación de un proyecto, por ejemplo. En cualquier caso, como apunta Amieva (2014, p. 235) ha de tenerse en cuenta que "[... . haciendo uso pedagógico de la deriva, se complejizan las relaciones tradicionales maestro/alumno, pues el pedagogo funciona más como un facilitador que como un profesor que enseña o transmite un conocimiento. [...] la deriva como herramienta pedagógica estaría bastante cercana al primer sentido etimológico de educere 'sacar a la luz' o a la mayéutica socrática”.

En un clima donde las preocupaciones de la relación de la educación con el entorno han sido ignoradas, hacer que el arte público participe en ella, ya sea en un entorno rural o urbano, es plantear una declaración física de resistencia y una visión diferente, una reivindicación del espacio público. Esas intervenciones de arte público ofrecen un modelo hacia el futuro, una mirada prescriptiva, apuntaba Duncum (2011, p. 353), una afirmación de cómo las personas quieren vivir con los demás y con ellos mismos. La deriva se encuentra aquí relacionada con el arte público, en tanto que se trata de aproximarse a la realidad urbana desde una mirada artística, para reconocer el territorio y sugerir la observación de estímulos susceptibles de generar una intervención en el espacio urbano o una obra artística posterior o abrir un proceso de creación multitextual. Sin embargo, si se considera desde una vía de implicación social en lugar de una interpelación directa crítica, el arte comunitario y vinculado al territorio se ven desafiados por los instrumentos del capitalismo global que erosionan simultáneamente las comunidades y degradan el entorno. Mientras que el tipo de pedagogía que adopta esta educación artística supone principalmente ofrecer una receta alternativa a las vías tradicionales del aula cercada por muros, el autor matiza que el artivismo (o arte público activista, o artivismo, entre otras denominaciones), es proporcionalmente opuesto a esta presión capitalista e institucional tradicional, ofreciendo compromiso y visiones más amplias para la función de plantar semillas de espíritu crítico en el alumnado, así como para poner en cuestión las formas de arte preestablecidas y discursos consolidados y sesgados por una sección de los poderes políticos, como puede ser el caso de la escultura estatuaria y los monumentos de personajes a caballo.

Francesco Careri (2014) resalta que tras la práctica asentada y la comprensión más en profundidad de la deriva, halla que esta conlleva un sentido de "proyecto indeterminado", en tanto que es instrumento para "construir una dirección': una 'situación lúdico-constructiva' (Debord) que 'deberá materializarse en forma de laberinto dinámico juntamente con los habitantes neobabilonenses' (Constant)" (Careri, 2014, p. 211) Entronca esta anotación con el carácter procesual de muchas intervenciones en el espacio público, intervenciones efímeras, performance, proyecciones audiovisuales y prácticas de acción, que subrayan la atención sobre el proceso, relacionado de alguna manera con aquellas manifestaciones de la cultura más próximas a la celebración, el evento, el ritual. Gran variedad de manifestaciones artísticas de los últimos años en el espacio colectivo provienen de estas formas de incursión en el entorno urbano y se encuentran explorando las vías más cercanas a la participación, interpelación, interacción e intervención, originando prácticas con un sentido de proceso abierto y vivo.

Me gustaría hablar ya no del andar para perderse, sino del andar para tropezar con el Otro, de la decisión de detenerse para construir un espacio de encuentro con lo diverso (Careri, 2014, p. 213).

Cabría, además, explorar la dimensión lúdica de la ciudad concebida por los situacionistas, que entronca con el concepto de juego tan presente en los campos de la educación, 
arte y arquitectura, y profundamente analizada su vinculación con el ser humano en la narración de Homo ludens, del historiador y teórico holandés Johan Huizinga (1938). Trachana (2012), presta especial atención a este tema, al afirmar que "[...] Es, por tanto, ámbito de la creación de una cultura espacial lúdica urbana que habría de implementarse con una paideia, un verdadero movimiento de cambio que penetre en todos los niveles de la educación y los diferentes ámbitos de socialización” (Trachana, 2012, p. 426).

Es en el ámbito de la investigación artográfica donde podemos hallar lugar a prácticas artísticas que exploran nuevos espacios de intención, tanto nuevos entornos físicos tridimensionales como sociales; y es en la ciudad donde podemos hallar un escenario integral en el que el aspecto pedagógico, no solo se encuentra en los confines del aula, sino que se entrelaza con el suceder de la vida urbana espontánea, cotidiana. La práctica artística encuentra multitud de condicionantes para llevarse a cabo en estas circunstancias específicas, pero, al mismo tiempo, descubre un nuevo campo de actuación del que rescatar saberes, reflexiones e inspiraciones, que no se manifiestan en otros contextos.

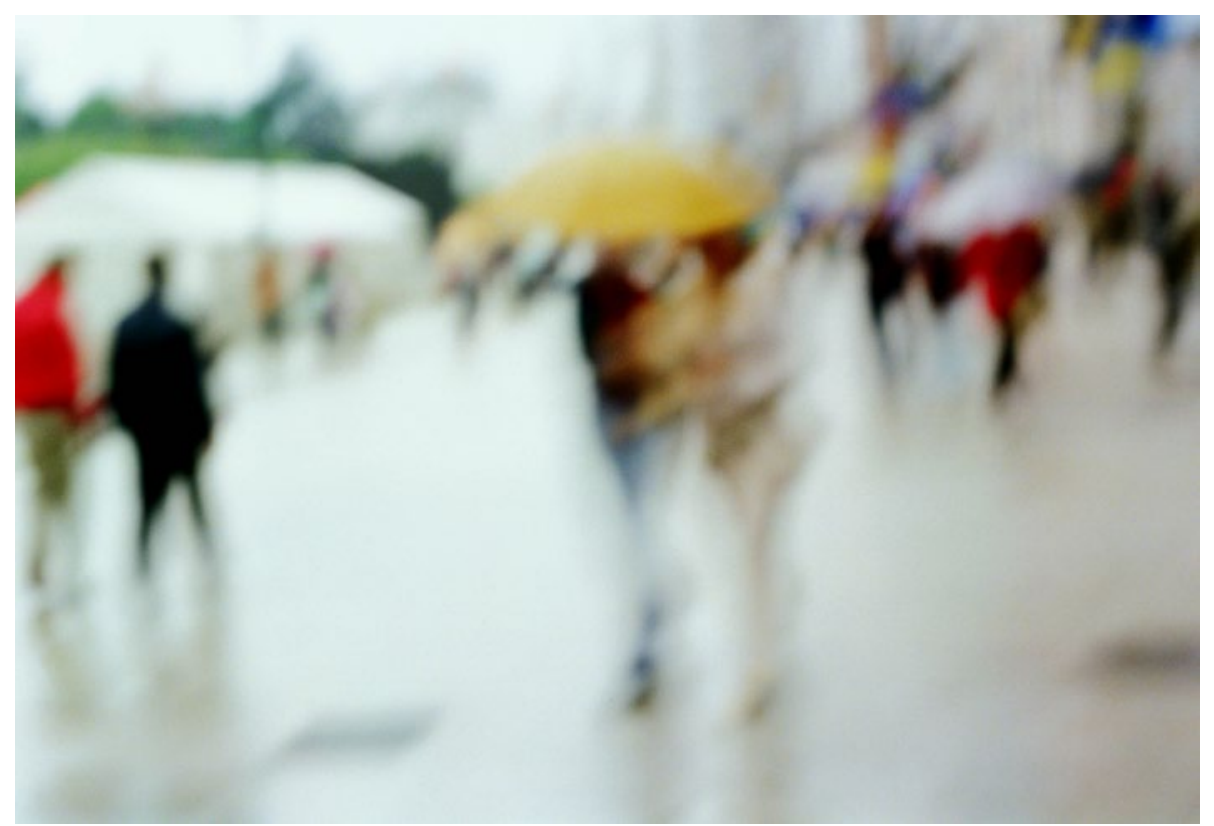

Imagen 14. Fotografía de la serie "Miraxes" de Vari Caramés.

“Para mí va más allá de lo que se ve, la esencia de los lugares viene dada por una combinación de estímulos percibidos por todos los sentidos. Un parque rural en verano cuando se oye el sonido de los pájaros y se respira un aire tan puro, que combinado con la calidez del sol en la piel, te lleva a un estado de paz. Sentarse en un banco a escuchar música en los cascos a esperar el bus entre el bullicio de una estación en la que la gente corre de un lado para otro, dándote la sensación de que todo va a cámara rápida a tu alrededor, de que el tiempo pasa demasiado rápido. Despertarte de la siesta en tu cama un día de verano y que la persiana y el sol se alíen para crear sombras en la pared que quieres capturar en una imagen porque también son arte. Si bien la definición de deriva puede no englobar todas estas cosas, yo me la llevo a mi terreno y la aplico no solo a derivar por espacios, sino también por sensaciones y pensamientos"

(Alumna EASD Pablo Picasso, 2020) 


\section{REFERENCIAS BIBLIOGRÁFICAS}

Alonso-Sanz, A. (2020) Una profesora flâneuse en París. Cartografías en la formación inicial de docentes. Arte, Individuo y Sociedad 32(2), 363-386. https://esbrina.eu/docs/ aprendo/simposi/G2a 1 Cartografias de una profesora Flaneuse en Paris.pdf

Amieva Montañez, M. (2014). La deriva situacionista como herramienta pedagógica. [Tesis doctoral, Universitat Antònoma de Barcelona]. https://www.tesisenred.net/hand$\underline{\text { le/10803/285390 }}$

Barone, T. \& Eisner, E. (2012). Arts based research [Investigación basada en el arte]. Sage.

Bassett, K. (2004). Walking as an aesthetic practice and a critical tool: Some psychogeographic experiments. Journal of Geography in Higher Education, 28(3), 397-410.

Brandt, M. (1930). Sin título. Fotomontaje, impresión. National Gallery of Art, Washington, Donación del Fondo Conmemorativo Pepita Milmore, R.K. Fundación de la Familia Mellon y Thomas Walther. http://archpapers.com/marianne-brandt-and-the-bauhaus-photomontages/

Caramés, V. (2003). Serie Miraxes. https://varicarames.com/miraxes-2003/

Carbonell Sebarroja, J. (2015). Pedagogías del siglo XXI. Alternativas para la innovación educativa. Octaedro Editorial.

Careri, F. (2002). Walkscapes: el andar como práctica estética. Gustavo Gili.

- - (2014). Walkscapes ten years after. URBS. Revista de Estudios Urbanos y Ciencias Sociales, 4(1), 207-213. http://www2.ual.es/urbs/index.php/urbs/article/view/careri

Debord, G. (1958). Teoría de la Deriva. En Internacional situacionista (I): La realización del arte (pp. 50-53). Literatura Gris, 1999.

Dérive App http://www.deriveapp.com

Duncum, P. (2011). Engaging Public Space: Art Education Pedagogies for Social Justice, Equity \& Excellence [Involucrar el espacio público: pedagogías de la educación artística para la justicia social, la equidad y la excelencia]. Education, 44(3), 348-363, DOI: 10.1080/10665684.2011.590400. http://dx.doi.org/10.1080/10665684.2011.590400

Foucault, M. (1999). Espacios diferentes. Estética, ética y hermenéutica (pp. 431-441). Paidós, 1967.

Genet Verney, R. (2016). Ciudad y educación en la formación del profesorado: Una investigación educativa basada en las artes visuales. [Tesis de doctorado, Universidad de Granada]. https://digibug.ugr.es/handle/10481/44551

Holmes, B. (2007). Investigaciones extradisciplinares. Hacia una nueva crítica de las instituciones. Multitudes, (28). https://marceloexposito.net/pdf/trad holmes extradisciplinares.pdf

Huerta, R. (2015). La ciudad y sus docentes. Miradas desde el arte y la educación.

- - - (2016). La ciudad desde el activismo y la cultura visual: hacia una mirada urbana del colectivo docente. Kult-ur, 3(6), 29-60. http://www.e-revistes.uji.es/index.php/kultur/article/view/1977

- - - (2018) Patrimonios de la educación artística: generar territorios propios desde un currículum vibrante. En Queiroz, J. P. (Ed.), Os riscos da arte: Formação e mediação [Los riesgos del arte: Formación y mediación] (pp. 93-104). Universidade de Lisboa. https:// www.academia.edu/38990424/Patrimonios de la Educaci\%C3\%B3n Art\%C3\%ADs- 
Martínez Bonafé, J. (2010). La ciudad en el curriculum y el curriculum en la ciudad. En Gimeno, J. (Ed.) Saberes e incertidumbres sobre el curriculum (pp. 527-546). Morata. https://www.uv.es/bonafe/El\%20curriculum\%20en\%20la\%20ciudad.pdf

Mesías-Lema, J. M. (2012). Fotografía y educación de las artes visuales: el fotoactivismo educativo como estrategia docente en la formación del profesorado. [Tesis de doctorado, Universidad de Granada]. https://digibug.ugr.es/handle/10481/23310

Miralles, E. (2005). Fotomontaje cartográfico. Agencia Pati Nuñez. Programa de Posgrado de Regeneración Urbana. Barcelona, España. https://www.archdaily.com/769457/ enric-miralles-foundation-to-offer-social-urban-regeneration-postgraduate-diploma

Nieuwenhuys, C. (1959). Ladderlabyrint. Museo Reina Sofía. Madrid, España. https:// stichtingconstant.nl/documentation/la-nueva-babilonia-la-ultima-utopia-europea

Nieuwenhuys, C. (1959). Serie New Babylon. Gemeentemuseum Den Haag. La Haya, Países Bajos. https://www.ensamblearquitectura.com/constant-and-the-situationistsnew-babylon-or-the-cities-of-the-future/

Ramon, R. \& Alonso-Sanz, A. (2019). La deriva paralela pedagógica. Un hilo educativo invisible entre Porto y Paris a través de narrativas personales. Revista Portuguesa de Educação [Revista Portuguesa de Educación], 32 (2). http://www.scielo.mec.pt/scielo. php?pid=S0871-91872019000200006\&script=sci abstract\&tlng=es

Trachana, A. (2012). Urbe Ludens: espacios para el juego en la ciudad. Ciudad y Territorio, XLVI (173), 423-444. 
Noelia Paz Fernández (Alperíz, Lalín - Pontevedra), estudió Bellas Artes en Valencia y Diseño Urbano en Barcelona. Realiza su práctica profesional en los campos de la Gestión Cultural (los últimos dos años en Ottawa, Canadá) y la Enseñanza de las Artes, combinando la creación y la investigación. Basa sus principios en el desarrollo social a través del arte. A través de la Escultura, del Vídeo y de la Teoría Estética, encuentra que es en los espacios públicos, colectivos donde se produce una comunicación directa del arte con la sociedad. Actualmente realiza un doctorado sobre arte rural contemporáneo.

noelia.pazfern@gmail.com 